\title{
Muscarinic Blockade Slows and Degrades the Location- Specific Firing of Hippocampal Pyramidal Cells
}

\author{
E. S. Brazhnik, ${ }^{1,2}$ R. U. Muller, ${ }^{1,3}$ and S. E. Fox ${ }^{1}$ \\ ${ }^{1}$ Department of Physiology and Pharmacology, State University of New York, Health Science Center at Brooklyn, Brooklyn, New York 11203, ${ }^{2}$ Institute of \\ Theoretical and Experimental Biophysics, Russian Academy of Science, Puschino, Russia 142292, and ${ }^{3}$ Medical Research Council Centre for Synaptic \\ Plasticity, Department of Anatomy, University of Bristol, Bristol, United Kingdom BS8 1TD
}

The firing of rat hippocampal pyramidal cells is determined both by the animal's location and by the state of the hippocampal EEG. Because cholinergic transmission plays a role in EEG activity, we expected that its modification would alter place cell activity. We therefore investigated the effects on place cell activity of blocking muscarinic transmission with intracerebroventricular injections of scopolamine.

Scopolamine reduced both the rate of place cell discharge inside firing fields and the spatial coherence of the fields; discharge outside of the fields also showed small increases. After injections, fields were shifted farther from their previous location than for saline controls, indicating reduced reproducibility after muscarinic blockade. Scopolamine increased the time rats were stationary, but changes in place cell activity persisted even after analysis was restricted to periods of walking, suggesting that the behavioral changes cannot account for the cell discharge changes. The scopolamine effects were dose dependent to an extent that varied between different measures.

The firing rates of interneurons showed only a minor trend to decrease after scopolamine. Nevertheless, the spatial coherence of interneuron firing patterns was reduced, consistent with the recent demonstration that their positional firing is mediated by the locationspecific firing of pyramids (Marshall et al., 2002).

These results demonstrate that acetylcholine enhances positional firing patterns in the hippocampus. Muscarinic blockade weakens the positional firing of most place cells and therefore renders them less useful for precise representation of the environment. This effect may underlie the difficulties in spatial learning and problem solving caused by abnormalities of cholinergic transmission.

Key words: muscarinic; cholinergic; place cell; hippocampus; theta rhythm; navigation

\section{Introduction}

In alert, freely moving rats the hippocampal EEG dwells mainly in one of two states. One state is called "large irregular activity" (LIA) (Vanderwolf, 1969) and is named for the sporadic "sharp waves," the features and significance of which have been well characterized (Csicsvari et al., 2000). The second state is called "rhythmic slow activity" (RSA) (Vanderwolf, 1969; Buzsaki, 2002) and is characterized by $5-12 \mathrm{~Hz}$ theta oscillations.

The presence of each EEG state is strongly correlated with the occurrence of certain behaviors (Vanderwolf, 1969). LIA is seen during eating, drinking, grooming, and quiet immobility. By contrast, RSA is seen during translational movements of the entire animal, including postural shifts, walking, and running.

Recording of pyramidal cells from freely moving rats reveals a second extremely strong signal, namely, the location-specific firing of place cells. Place cells discharge rapidly only if the rat's head is in a cell-specific part of the environment called the place field. The signaling of location by place cells and the occurrence of a

Received May 7, 2002; revised 0ct. 3, 2002; accepted 0ct. 8, 2002.

This work was supported by National Institutes of Health Grants NS 17095 to S.E.F. and NS20686 and NS 37150 to R.U.M. and by a United Kingdom Medical Research Council Centre Overseas Initiative Grant to R.U.M. We thank L. Eberle and Dr. E. Hawley for technical support. We also thank the two anonymous reviewers for their helpful comments.

Correspondence should be addressed to Steven E. Fox, Department of Physiology and Pharmacology, Box 31 State University of New York, Health Science Center at Brooklyn, 450 Clarkson Avenue, Brooklyn, NY 11203. E-mail: steve@theta.downstate.edu.

Copyright $\odot 2003$ Society for Neuroscience $\quad 0270-6474 / 03 / 220611-11 \$ 15.00 / 0$ certain EEG state during changes of location seem unavoidably connected and are two fundamental underpinnings of the spatial mapping theory of hippocampal function (O'Keefe and Nadel, 1978).

A close relationship between the hippocampal EEG and place cells is suggested by several independent lines of evidence. First, immobilizing rats can abolish place cell discharge (Foster et al., 1989), although less severe movement restrictions have weaker consequences (Kubie et al., 1985). Second, place cell action potentials systematically shift relative to the theta cycle as a rat crosses a place field (O'Keefe and Recce, 1993; Skaggs et al., 1996). Finally, the in-field firing rate goes up and the out-of-field rate goes down at the transition from LIA to theta, enhancing the spatial signal (Kubie et al., 1985).

To further investigate the EEG/place cell relationship, we took advantage of the demonstration that the theta rhythm accompanying movement has a cholinergic component. In addition to movement-related theta, a second form precedes abrupt translational movement (Vanderwolf, 1969) so that in rats trained to jump out of a box to avoid shock the LIA-theta transition occurs $\sim 1$ sec before the jump, while the rat remains still. Centrally acting muscarinic antagonists abolish this initial theta that normally occurs during the immobility preceding movement but have little apparent effect on "atropine-resistant theta" during translational movements. Atropine-sensitive theta is not confined, however, to periods when the animal is not moving but normally coexists with atropine-resistant theta during ongoing 
movements. Thus, lesions that abolish the atropine-resistant theta have little obvious effect on theta during movement, but after such lesions theta is abolished by atropine (Vanderwolf et al., 1985).

We therefore asked how blockade of muscarinic transmission affects place cell firing. To reduce the possible loci of action, scopolamine was injected into the lateral ventricles, not systemically. Scopolamine acts in a dose-dependent way such that place cell discharge during theta comes to resemble the spatially weaker signals seen during LIA.

Some of these results have been published previously in preliminary form (Brazhnik et al., 1994).

\section{Materials and Methods}

The basic methods are adapted from Muller et al. (1987).

Recording apparatus. Recordings were made while rats ran around inside a 76-cm-diameter, 51-cm-high gray cylinder. Attached to the inside wall of the cylinder was a white cue card that occupied $90^{\circ}$ of the circumference. The cylinder was centered inside a 2-m-diameter circular curtain that visually isolated the cylinder from the $3 \times 3 \mathrm{~m}$ recording room. Lighting was provided by four $25 \mathrm{~W}$ bulbs arranged at the vertices of a square $2 \mathrm{~m}$ above the apparatus floor. The cylinder floor was made of gray photographic backdrop paper that was replaced between each pair of training or recording sessions. During training and recording the door to the experimental room was closed, but no additional precautions were taken to eliminate sound sources that might provide directional information for the rats. Nevertheless, under these circumstances, rotations of the white cue card in the rat's absence reliably control the angular location of place cell firing fields (Muller et al., 1987; Kentros et al., 1998).

Subjects and training. All treatment of animals followed institutional and National Institutes of Health guidelines. The subjects were 10 male Long-Evans hooded rats $(240-350 \mathrm{gm})$ that were trained in two stages after food deprivation to $85 \%$ of ad libitum weight. First, each rat was put into the cylinder after $\sim 30$ food pellets $(20 \mathrm{mg}$ ) were scattered on the floor. After several 10-20 min sessions, rats readily retrieved and ate the pellets. Second, $20 \mathrm{mg}$ pellets were dropped at random locations by an overhead feeder at an average rate of three per minute during $16 \mathrm{~min}$ training sessions. After three or more training sessions, rats found and ate virtually all of the pellets and in the process visited all parts of the recording cylinder.

Surgery and electrode implantation. After training, two separate electrode assemblies were put into the rat's brain under Nembutal anesthesia $(40 \mathrm{mg} / \mathrm{kg})$. The first was for unit recording and consisted of a bundle of 10 insulated $25 \mu \mathrm{m}$ nichrome microwires that could be moved through the rat's brain (Kubie, 1984); the electrodes were cut square and implanted above either CA1 (eight rats) or CA3 (two rats). The second assembly was for EEG recording and consisted of two straight $150 \mu \mathrm{m}$ nichrome wires glued to each other with one cut $0.7-1.0 \mathrm{~mm}$ shorter than the other. The EEG electrodes were placed in the hippocampus contralateral to the single unit bundle and fixed with the longer electrode at anteroposterior (AP) $3.5 \mathrm{~mm}$, lateral (L) $2.5 \mathrm{~mm}$, (H) $2.4 \mathrm{~mm}$, with respect to bregma, aimed at the hippocampal fissure (fissure theta) and the shorter electrode aimed just dorsal to CA1 stratum pyramidale (CA1 theta). In addition to the electrodes, the end of a 28 gauge stainless steel cannula was implanted in each lateral ventricle at AP $-1 \mathrm{~mm}, \mathrm{~L} 3.6 \mathrm{~mm}$, $\mathrm{H} 3.2 \mathrm{~mm}$. The cannulas were in the coronal plane and angled at $30^{\circ}$ toward the midline going from the top to the ventricle termination. Rats were allowed 1-2 weeks for recovery from surgery before recordings were started.

Recordings. Extracellular single-unit activity from complex-spike cells [pyramidal cells of CA1 and CA3 (Fox and Ranck, 1975)] and theta cells [hippocampal interneurons (Fox and Ranck, 1981)] were recorded simultaneously with hippocampal EEG activity using a Datawave (Longmont, $\mathrm{CO}$ ) workstation. The single-unit channels were amplified by 5000 , bandpass filtered from 300 to $10,000 \mathrm{~Hz}$, and digitized at 33,00040,000 samples per second. The EEG channels were amplified by 1000 , bandpass filtered from 0.3 to $300 \mathrm{~Hz}$, and digitized at $1000 \mathrm{~Hz}$. Hippocampal neurons were classified according to (1) properties of unitary waveforms including the generation of complex-spikes and waveform duration, (2) temporal firing pattern, and (3) depth within the hippocampal strata as determined from initial electrode placement and turns of the drive screws of the single-unit bundle.

Thus, to be considered a pyramidal cell, a target neuron had to generate complex spikes (bursts of action potentials with decrementing amplitude and interspike intervals of $<10 \mathrm{msec}$ ). In addition, the duration of the initial, negative phase of the single spikes had to be more than $\sim 0.3$ msec. Cells with these waveform characteristics are almost invariably characterized by the existence of very long $(>1 \mathrm{sec})$ interspike intervals as well as briefer intervals and may be silent for many seconds at a time. In general, such cells are found within the boundaries of stratum pyramidale as judged from electrode placement and movement.

To be considered a theta cell, a candidate unit could never generate a complex burst and had to have an initial negative waveform component waveform $<0.25 \mathrm{msec}$ in duration. Cells with these waveform properties never showed interspike intervals $>0.25 \mathrm{sec}$. In addition, their activity was clearly phase locked to the $5-10 \mathrm{~Hz}$ sine-like "theta" EEG rhythm when it was present. Furthermore, the average firing rate of these cells approximately doubled when the EEG pattern entered the theta state. CA1 neurons classified as theta cells were generally found in stratum oriens or superficial stratum pyramidale. In general, CA3 theta cells were recorded simultaneously with CA3 pyramidal cells.

To reduce the likelihood of confusion between spikes generated by more than one cell, we used only waveforms $>200 \mu \mathrm{V}$ in peak-to-peak amplitude. Waveforms were also sorted using detailed characteristics such as small positivities preceding the negativity associated with the upswing of the intracellular action potential. Finally, it is important to note that sorting errors would not affect any of the key results because we are concerned with modifications of spatial firing patterns and not with specific firing pattern properties such as the number of firing fields.

The reference electrode for both EEG recordings was a skull screw placed over the cerebellum. When the EEG was in the theta state, the two channels were phase reversed relative to each other. In EEG recordings, the positive phase of theta is displayed upward.

Pharmacological manipulations. Recordings were made before, during, and after intracerebroventricular injections of scopolamine, a broadaction muscarinic cholinergic antagonist. The drug was injected over a 1 min interval into each ventricle with 2 min between the injections. The usual dose of scopolamine was $3.0 \mu \mathrm{g}$ in $1 \mu \mathrm{l}$ of saline per ventricle because preliminary work showed that this caused little or no ataxia and did not impair the efficiency of pellet retrieval. Higher doses of scopolamine (100 $\mu$ g, i.c.v., in $20 \mu \mathrm{l}$ of saline) have been reported to increase exploratory activity in an open field, whereas intracerebroventricular doses $>1000 \mu \mathrm{g}$, near the $\mathrm{LC}_{50}$, produce narcosis (Zebrowska-Lupina et al., 1975). Our experiments were performed at doses well below these levels. Dose-response curves were obtained by using 1.5, 3.0, and $6.0 \mu \mathrm{g}$ scopolamine in $1 \mu \mathrm{l}$ of saline per ventricle.

The positional firing patterns of one or more hippocampal neurons were recorded before a scopolamine injection and then several times afterward to determine the time course of the effect. Postinjection recordings were made at $30 \mathrm{~min}, 60 \mathrm{~min}$, and then at $60 \mathrm{~min}$ increments for up to $5 \mathrm{hr}$ as long as cell waveforms remained recognizable with the cluster-cutting software provided by Datawave. In addition, identified cells could often be held for $24 \mathrm{hr}$ after scopolamine injection so that it was possible to look for recovery. Because place cell activity was clearly depressed during the first $6 \mathrm{hr}$ after bilateral injections of $3.0 \mu \mathrm{g}$ scopolamine per ventricle but generally returned to preinjection levels the next day, additional scopolamine injections in the same animal were separated by at least $3 \mathrm{~d}$ and often by $5 \mathrm{~d}$. The same protocol was used for recordings made after control injections of $1 \mu \mathrm{l}$ of saline into both ventricles.

Data collection and analysis. Single-unit activity, EEG signals, and the rat's position were recorded simultaneously during 16 min sessions. Positional discharge patterns were visualized by constructing color-coded firing rate maps. First, the number of spikes and total dwell time were accumulated for each $2.4 \times 2.4 \mathrm{~cm}$ pixel visited by the rat. Next, the time-averaged positional firing rate distribution was calculated by dividing, on a pixel-by-pixel basis, the dwell time into the number of spikes. 
Finally, pixels for the predrug session were assigned to a color category according to an autoscaling algorithm such that discharge rates were coded in the order orange, red, green, blue, and purple; pixels in which the firing rate was exactly zero were colored yellow, and pixels never entered by the rat were coded white. Because place cell discharge is tightly confined to firing fields, such fields appear as dark regions on a yellow background. This scheme ensures that the fraction of pixels in each greater than zero rate category is constant for the predrug session for all cells. The autoscaled color-category ranges from the predrug control sessions for each cell were also used for the illustrations of the recording sessions that followed drug injection.

To visualize changes in firing rates or in the size or shape of firing fields, the firing rate boundaries between color categories from the preinjection session for a given cell were applied to the color-coded maps for all postinjection sessions for that cell.

Several quantitative measurements were used to describe the positional firing patterns of place cells and theta cells before and after drug administration. Field size was taken as the number of pixels in the largest continuous area in which the firing rate was greater than zero; to be included with other pixels, a given pixel had to share an edge with at least one other pixel in the field. Discharge intensity was estimated in four ways: (1) the grand average, position-independent firing rate (overall rate); (2) the mean rate inside the field (in-field rate); (3) the maximum rate of firing, which is the highest average firing rate in the $3 \times 3$ region centered on each pixel (this is referred to as center rate to indicate maximum rate in the center of the field for place cells and as peak rate for theta cells, because for them there is no discrete field); and (4) the outof-field rate, which is the average rate for all pixels not part of the field. In addition we calculated the ratio of the in-field rate to out-of-field rate (in/out ratio) as an estimate of the positional signal-to-noise ratio.

The local smoothness of positional firing patterns was estimated by calculating coherence, which is a nearest-neighbor, two-dimensional autocorrelation. Numerically, coherence is the correlation between the firing rate in a pixel and the average rate in its eight nearest neighbors. Pixel-by-pixel cross-correlation between maps for pairs of sessions provided a similarity score. The maps were rotated with respect to each other to compute rotational cross-correlation profiles to find the amount of rotation necessary to maximize the similarity score. In this way it is possible to determine whether a field remains in a constant position between session pairs and to ask whether cue card rotations cause equal rotations of firing patterns. The magnitude of the maximal correlation between the fixed and rotated patterns (maximum similarity) estimates the similarity of the two positional firing patterns regardless of rotation angle (change in angle). The average change in angle across cells looks for systematic directional field rotations after a manipulation. If there is no systematic directional field rotation, then the average of the absolute value of the change in angle (absolute change in angle) estimates the amount of angular error of field location between two sessions. In these experiments, these measures compared pairs composed of two control sessions with pairs composed of a control session and a standard $1 \mathrm{hr}$ scopolamine session.

Multivariate ANOVAs were used to determine whether dependent variables (overall rate, in-field rate, center rate, out-of-field rate, in/out ratio, field size, coherence) were systematically changed by time (control vs control), drug administration, anatomical locus (CA1 vs CA3), drug dose, or time after drug administration. In the event of significant multivariate ANOVA effects, pairwise comparisons were made with Fisher's protected least significant difference (PLSD). These calculations were performed using the Statview 5.01 statistical analysis package from SAS Institute.

The EEG data were recorded onto analog tape during the place cell recording sessions and analyzed separately. For the power spectral analysis of the theta rhythm, the hippocampal EEG was anti-alias filtered $(-24 \mathrm{~dB}$ /octave above $30 \mathrm{~Hz})$ and sampled at $100 \mathrm{~Hz}$. The mean magnitude of the peak in the theta band $(5.9-9.8 \mathrm{~Hz})$ was computed for 100 contiguous EEG segments of $5.12 \mathrm{sec}$ each (the first $8.5 \mathrm{~min}$ of the recording session).

To determine phase relationships between unit discharge and theta rhythm, phase histograms were constructed from EEG, and spike data were recorded during sessions at least $10 \mathrm{~min}$ long. Data for phase histograms were selected using a Fourier-based "theta score" (Fox et al., 1986) as follows. First, each EEG signal was digitally bandpass filtered between 5.2 and $8.9 \mathrm{~Hz}$, and the autocorrelation functions were obtained. The autocorrelation functions were then normalized relative to the total unfiltered EEG power integrated across all frequencies. Finally, the theta score is the root-mean-square value of the autocorrelation function computed for time lags up to $1.28 \mathrm{sec}$. The theta score takes on values in the range $0.0-1.0$ such that a pure sine wave in the band between 6 and $8 \mathrm{~Hz}$ yields a score of 1.0, whereas broadband noise yields scores below 0.1 . This theta score was used both as a criterion for inclusion of data into phase histograms and to determine the fraction of time the EEG was in the theta state.

EEG and spike data were included in the phase histograms for continuous epochs in which the theta score was $>0.35$. For such epochs, the positive peaks bounding each theta cycle at the hippocampal fissure (fissure theta) were found. If the interval between these peaks was between 112 and $192 \mathrm{msec}$, this "theta wave" was normalized into 32 phase bins. Spikes were assigned to a phase according to the real time at which they occurred during the theta wave. An averaged theta waveform was computed by normalizing the duration of each theta wave into 32 bins and then averaging each bin; this was done separately for the dentate and CA1 EEG sites. This phase histogram analysis was used both to measure the average phase of firing of place cells and theta cells with respect to the fissure theta and to measure the amplitude of the averaged theta waves uncontaminated by non-theta EEG.

Histology. At the end of recordings for a rat, the animal was killed with a lethal injection of Nembutal and perfused transcardially first with saline and then $10 \%$ formalin. Frozen $40 \mu \mathrm{m}$ sections were stained with cresyl violet to confirm the positions of the cannulas and EEG electrodes and the final position of the unit recording bundle.

\section{Results}

\section{Cell activity is constant before scopolamine injections}

To enhance the likelihood that discriminable waveforms found before injections could be held long enough to determine the time course of scopolamine action and to test the constancy of cell properties, we often did two preinjection sessions. In general, as long as the waveforms were stable across the two preinjection sessions, no systematic changes were found in discharge properties of place cells or theta cells (Table 1). This constancy of hippocampal cell activity in fixed conditions is in line with a great deal of previous work (Muller et al., 1987; Kubie et al., 1990; Thompson and Best, 1990; Bostock et al., 1991). We recorded a total of 23 place cells ( 13 in CA1 and 10 in CA3) and 17 theta cells ( 7 in CA1 and 10 in CA3) before and $1 \mathrm{hr}$ after injecting $1.0 \mu \mathrm{l} \mathrm{of}$ saline into each lateral ventricle. As shown by multivariate ANOVA, no reliable changes were seen in any of the parameters used to characterize the firing properties of either place cells or theta cells (Table 2). The magnitude of the small changes that were observed were comparable with those seen between two control recordings. A second multivariate ANOVA taking into account location in CA1 or CA3 as well as cell type also failed to reveal any reliable changes after saline injections (data not shown). We conclude that intracerebroventricular injections of inert materials do not by themselves affect either place cell or theta cell activity in CA1 and CA3.

\section{Comparison of the properties of CA3 and CA1 cells}

We saw small differences in firing rate (measured in three ways) between CA3 and CA1 place cells (Table 3, top): the CA3 cells were $22 \%$ slower according to overall rate, $17 \%$ slower according to field-center rate, and 25\% slower according to overall in-field rate. The average coherence was the same for cells in both CA1 and CA3 despite the marginally lower firing rates of CA3 cells. A rotational analysis (see Materials and Methods) revealed that fir- 
Table 1. Comparison of two control recordings

\begin{tabular}{|c|c|c|c|c|c|c|c|c|c|}
\hline \multirow[b]{2}{*}{ Cell type } & \multirow[b]{2}{*}{ Characteristic } & \multicolumn{2}{|c|}{ First session } & \multicolumn{2}{|c|}{ Second session } & \multirow[b]{2}{*}{$n$ (cells) } & \multirow[b]{2}{*}{$F$} & \multirow[b]{2}{*}{ df } & \multirow[b]{2}{*}{$p$} \\
\hline & & Mean & SD & Mean & SD & & & & \\
\hline \multirow[t]{7}{*}{ Place cells } & Overall rate & 2.83 & 2.54 & 2.82 & 2.55 & 69 & 0.001 & 1,136 & 0.973 \\
\hline & In-Field rate & 5.78 & 3.27 & 5.26 & 2.82 & 69 & 0.996 & 1,136 & 0.320 \\
\hline & Center rate & 18.5 & 9.8 & 18.0 & 9.4 & 69 & 0.106 & 1,136 & 0.745 \\
\hline & Out-of-field rate & 0.61 & 0.66 & 0.67 & 0.78 & 69 & 0.170 & 1,136 & 0.680 \\
\hline & In/out ratio & 51.6 & 148.1 & 32.2 & 41.4 & 69 & 1.096 & 1,136 & 0.297 \\
\hline & Field area & 184 & 114 & 213 & 113 & 69 & 2.250 & 1,136 & 0.136 \\
\hline & Coherence & 0.82 & 0.28 & 0.87 & 0.30 & 69 & 1.100 & 1,136 & 0.296 \\
\hline \multirow[t]{3}{*}{ Theta cells } & Overall rate & 17.3 & 8.4 & 16.9 & 7.5 & 16 & 0.023 & 1,30 & 0.880 \\
\hline & Peak rate & 37.2 & 19.0 & 37.7 & 17.3 & 16 & 0.008 & 1,30 & 0.932 \\
\hline & Coherence & 0.58 & 0.35 & 0.51 & 0.27 & 16 & 0.349 & 1,30 & 0.559 \\
\hline
\end{tabular}

Table 2. Effect of saline injection on place cells and theta cells

\begin{tabular}{|c|c|c|c|c|c|c|c|c|c|}
\hline \multirow[b]{2}{*}{ Cell type } & \multirow[b]{2}{*}{ Characteristic } & \multicolumn{2}{|l|}{ Control } & \multicolumn{2}{|l|}{ Saline } & \multirow[b]{2}{*}{$n$ (cells) } & \multirow[b]{2}{*}{$F$} & \multirow[b]{2}{*}{ df } & \multirow[b]{2}{*}{$p$} \\
\hline & & Mean & SD & Mean & SD & & & & \\
\hline \multirow[t]{7}{*}{ Place cells } & Overall rate & 2.19 & 1.97 & 1.86 & 1.49 & 23 & 0.398 & 1,44 & 0.531 \\
\hline & In-Field rate & 4.68 & 2.09 & 4.27 & 1.82 & 23 & 0.492 & 1,44 & 0.487 \\
\hline & Center rate & 14.4 & 8.5 & 13.1 & 8.1 & 23 & 0.314 & 1,44 & 0.578 \\
\hline & Out-of-field rate & 0.42 & 0.40 & 0.32 & 0.30 & 23 & 0.956 & 1,44 & 0.333 \\
\hline & In/out ratio & 27.0 & 27.3 & 28.1 & 27.1 & 23 & 0.019 & 1,44 & 0.890 \\
\hline & Field area & 161 & 121 & 155 & 119 & 23 & 0.028 & 1,44 & 0.867 \\
\hline & Coherence & 0.89 & 0.26 & 0.88 & 0.30 & 23 & 0.022 & 1,44 & 0.882 \\
\hline \multirow[t]{3}{*}{ Theta cells } & Overall rate & 12.4 & 10.3 & 12.5 & 11.4 & 17 & 0.002 & 1,32 & 0.966 \\
\hline & Peak rate & 31.5 & 16.8 & 30.4 & 18.4 & 17 & 0.031 & 1,32 & 0.860 \\
\hline & Coherence & 0.61 & 0.26 & 0.66 & 0.23 & 17 & 0.238 & 1,32 & 0.629 \\
\hline
\end{tabular}

Table 3. Comparison of $\mathrm{CA} 1$ and $\mathrm{CA} 3$

\begin{tabular}{|c|c|c|c|c|c|c|c|c|c|c|}
\hline \multirow[b]{2}{*}{ Cell type } & \multirow[b]{2}{*}{ Characteristic } & \multicolumn{3}{|c|}{ CA1 Controls } & \multicolumn{3}{|c|}{ CA3 Controls } & \multirow[b]{2}{*}{$F$} & \multirow[b]{2}{*}{ df } & \multirow[b]{2}{*}{$p$} \\
\hline & & Mean & SD & $n$ (cells) & Mean & SD & $n$ (cells) & & & \\
\hline \multirow[t]{7}{*}{ Place cells } & Overall rate & 2.53 & 2.39 & 126 & 1.95 & 1.59 & 94 & 4.16 & 1,218 & $0.043^{*}$ \\
\hline & In-field rate & 5.15 & 3.03 & 126 & 3.88 & 1.87 & 94 & 12.97 & 1,218 & $<0.001^{*}$ \\
\hline & Center rate & 16.2 & 9.6 & 126 & 13.4 & 8.0 & 94 & 5.06 & 1,218 & $0.026^{*}$ \\
\hline & Out-of-field rate & 0.79 & 1.01 & 126 & 0.72 & 0.74 & 94 & 0.33 & 1,218 & 0.567 \\
\hline & In/out ratio & 38.4 & 112.9 & 126 & 17.9 & 25.7 & 94 & 2.96 & 1,218 & 0.087 \\
\hline & Field area & 168 & 118 & 126 & 190 & 128 & 94 & 1.83 & 1,218 & 0.178 \\
\hline & Coherence & 0.72 & 0.29 & 126 & 0.72 & 0.33 & 94 & 0.00 & 1,218 & 0.964 \\
\hline \multirow[t]{3}{*}{ Theta cells } & Overall rate & 15.9 & 7.9 & 24 & 16.6 & 16.0 & 10 & 0.03 & 1,32 & 0.874 \\
\hline & Peak rate & 36.3 & 16.1 & 24 & 24.0 & 7.6 & 10 & 0.04 & 1,32 & 0.853 \\
\hline & Coherence & 0.52 & 0.24 & 24 & 0.66 & 0.44 & 10 & 1.40 & 1,32 & 0.246 \\
\hline
\end{tabular}

${ }^{*} p<0.05$.

ing fields in both regions stayed in the same location in pairs of control sessions. Thus, the absolute rotation necessary to produce the best superimposition was only $3^{\circ}$ for CA 1 and $4^{\circ}$ for CA3. Furthermore, the maximum correlations were high $(0.68$ for CA1 and 0.64 for CA3) and no different from each other. No differences were seen in the properties of theta cells in CA1 and CA3 (Table 3, bottom).

\section{Place cell activity is weakened by bilateral} intracerebroventricular injections of $3.0 \mu \mathrm{g}$ of scopolamine Preliminary work showed that injections of $3.0 \mu \mathrm{g}$ of scopolamine in $1.0 \mu \mathrm{l}$ of saline into both cerebral ventricles markedly decreased the in-field discharge of CA1 place cells. This reduction of place cell activity was not accompanied by abnormal locomotion. Moreover, as judged from the continued efficacy of foraging for food pellets, this amount of scopolamine did not interfere with at least basic sensory functions or motivation. Accordingly, $3.0 \mu \mathrm{g}$ of scopolamine in $1.0 \mu \mathrm{l}$ of saline was selected as the standard drug dose, and most of our data were obtained after such injections.

The effects of a $3.0 \mu \mathrm{g}$ dose of scopolamine $1 \mathrm{hr}$ after injection are seen by comparing the firing rate maps in the third row of Figure 1 with the maps for control sessions in the first row. (Compare also the second row with the first row of rate maps in Fig. 2.) The impression of weaker, somewhat disorganized positional firing patterns for place cells is confirmed in several ways in Table 4. First, it is clear that the overall, field center, and in-field rates all decrease for both CA1 and CA3 place cells. For the CA1 place cells there is a trend for out-of-field rate to increase, but the main contribution to the barely significant ratio of in-field to out-offield firing rate is the decreased in-field firing. For CA3 place cells, there is an even smaller increase of out-of-field rate, and the ratio of in-field to out-of-field firing rate does not approach significance. For both CA1 and CA3 place cells the size of the largest firing field showed a tendency to decrease, but this effect was weak. Several place cells (six in CA1, eight in CA3) showed an 


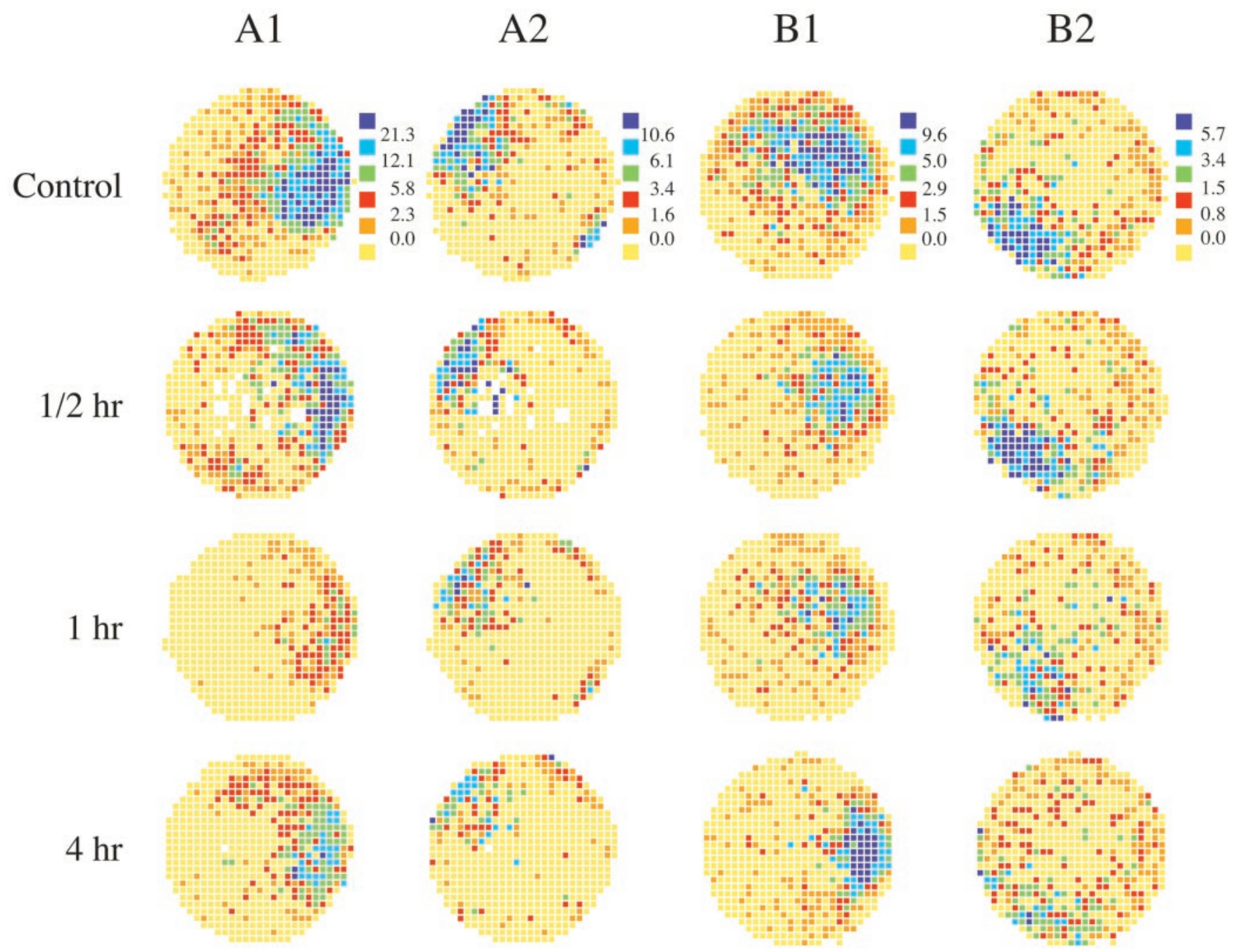

Figure 1. Spatial firing pattern for two pairs of simultaneously recorded hippocampal cells before and at $0.5,1$, and $4 \mathrm{hr}$ intervals after blockade of muscarinic transmission by scopolamine ( $3 \mu \mathrm{g}$ per ventricle). Each circle is a color-coded firing rate map indicating the discharge rate of a place cell as a function of the position of a rat's head on the floor of a cylindrical chamber. Yellow pixels mark positions where no action potentials ever occurred. Orange, red, green, blue, and purple represent increasing firing rates where the breakpoints between color categories are taken from the control session for each cell; these breakpoints are indicated at the right of the control map for each cell. Muscarinic blockade caused a significant and long-lasting decrease in the firing rate of place cells throughout the field.

initial transient increase in their in-field firing rate in the $0.5 \mathrm{hr}$ time point before the decrease that followed in the $1 \mathrm{hr}$ and later time points. A few place cells (three in CA1, three in CA3) exhibited a sustained firing rate increase for up to $6 \mathrm{hr}$ after injection.

In addition to the overall tendency for firing rates to decrease $1 \mathrm{hr}$ after a standard scopolamine dose, we also saw for both CA1 and CA3 place cells very robust decreases of field smoothness, as measured by coherence (Table 4). The lower coherence is probably partly secondary to decreases of firing rate, but direct inspection of firing rate maps (Figs. 1,2) indicates that the local precision of location-specific firing is disrupted. The idea that location-specific firing is less accurate in CA1 and CA3 after scopolamine injections is reinforced by the much larger mean absolute angle needed to maximize the similarity of control and scopolamine sessions compared with the angle required to maximize the similarity of pairs of control sessions (Table 4). The reduced mean maximal correlation after scopolamine is yet another indication that spatial firing is disrupted more severely than would be expected from firing rate reductions alone.

Despite the derangement of place cell firing patterns $1 \mathrm{hr}$ after a standard scopolamine dose, it is important to realize that the firing patterns did not undergo the "complete remapping" process that may occur after sufficiently strong changes in the environment (Muller et al., 1987; Kentros et al., 1998). Thus, the mean similarity at $0^{\circ}$ rotation is 0.279 , which is significantly $>0$ $(t=6.67 ; \mathrm{df}=57 ; \mathrm{p} \ll 0.001)$. As a control measure, we also computed the mean correlation between randomized pairs of these same cells and found that after this shuffling of the cell pairings the correlation is reduced to -0.008 , which is indistinguishable from $0(t=0.36$; $\mathrm{df}=57 ; p=0.72)$. By this criterion, the loss of spatial information caused by scopolamine is only partial.

In contrast to the clear effects of muscarinic blockade on place cell activity, the only reliable modification of theta cell activity was for coherence in CA3; there was also a trend for such a reduction in CA1. These results are documented in Table 4.

\section{EEG and behavioral effects of the standard scopolamine injection}

In an earlier work (Kubie et al., 1985), we found that the degree to which place cell discharge was restricted to firing fields varied as a function of the state of the hippocampal EEG. Thus, when the 


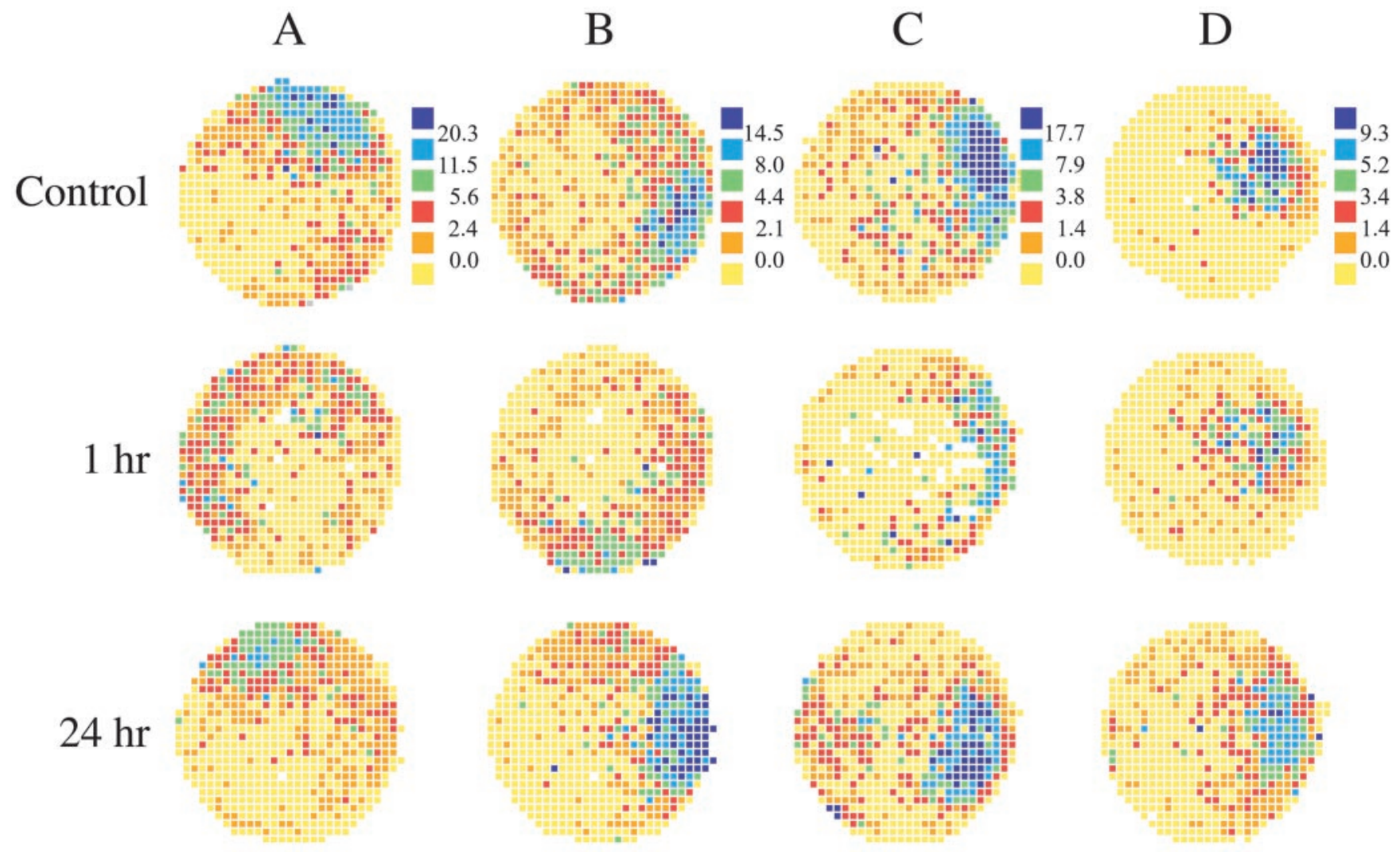

Figure 2. Recovery of place fields after $24 \mathrm{hr}$. The spatial firing patterns of four hippocampal pyramidal cells $(A-D)$ are coded as in Figure 1 . Firing rate maps are given for control sessions and sessions $1 \mathrm{hr}$ and $24 \mathrm{hr}$ after muscarinic blockade. Firing rate decreases, loss of spatial organization, and motion of the entire field are visible at $1 \mathrm{hr}$ but mainly reversed by $24 \mathrm{hr}$.

Table 4. Effect of scopolamine injection

\begin{tabular}{|c|c|c|c|c|c|c|c|c|c|}
\hline \multirow[b]{2}{*}{ Cell type } & \multirow[b]{2}{*}{ Characteristic } & \multicolumn{2}{|l|}{ Control } & \multicolumn{2}{|c|}{ Scopolamine } & \multirow[b]{2}{*}{$n$ (cells) } & \multirow[b]{2}{*}{$F$} & \multirow[b]{2}{*}{ df } & \multirow[b]{2}{*}{$p$} \\
\hline & & Mean & SD & Mean & SD & & & & \\
\hline \multirow[t]{10}{*}{ Place cells } & Overall rate & 2.77 & 2.35 & 1.80 & 1.68 & 110 & 12.5 & 1,218 & $<0.001^{*}$ \\
\hline & In-field rate & 5.61 & 2.95 & 3.60 & 1.91 & 110 & 36.2 & 1,218 & $<0.001^{*}$ \\
\hline & Center rate & 18.7 & 9.3 & 11.3 & 7.1 & 110 & 43.5 & 1,218 & $<0.001^{*}$ \\
\hline & Out-of-field rate & 0.65 & 0.78 & 0.88 & 1.01 & 110 & 3.7 & 1,218 & 0.057 \\
\hline & In/out ratio & 42.6 & 118.7 & 16.7 & 31.2 & 110 & 4.9 & 1,218 & $0.028^{*}$ \\
\hline & Field area & 199 & 123 & 155 & 119 & 110 & 7.1 & 1,218 & $0.008^{*}$ \\
\hline & Coherence & 0.87 & 0.26 & 0.56 & 0.28 & 110 & 72.0 & 1,218 & $<0.001^{*}$ \\
\hline & Change in angle & 1 & 6 & -1 & 49 & 53 & 0.0 & 1,104 & 0.831 \\
\hline & Absolute change in angle & 3 & 5 & 30 & 39 & 53 & 24.8 & 1,104 & $<0.001^{*}$ \\
\hline & Maximum similarity & 0.67 & 0.17 & 0.38 & 0.28 & 53 & 41.2 & 1,104 & $<0.001^{*}$ \\
\hline \multirow[t]{3}{*}{ Theta cells } & Overall rate & 16.1 & 10.6 & 12.2 & 9.9 & 34 & 2.5 & 1,66 & 0.120 \\
\hline & Peak rate & 35.9 & 18.4 & 31.4 & 20.7 & 34 & 0.9 & 1,66 & 0.346 \\
\hline & Coherence & 0.56 & 0.31 & 0.38 & 0.27 & 34 & 6.1 & 1,66 & $0.016^{*}$ \\
\hline
\end{tabular}

${ }^{*} p<0.05$.

EEG switched from the theta state (characterized by $5-12 \mathrm{~Hz}$ sine-like waves) to LIA (characterized by sporadic highamplitude spikes), the in-field rate decreased and the out-of-field rate increased, producing a considerable decrease in spatial signal to noise. We therefore asked whether scopolamine could exert its effect simply by causing the EEG to spend a greater fraction of its time in the LIA state.

We first found that the standard scopolamine dose reduced the peak power in the $5-12 \mathrm{~Hz}$ theta band by $33 \pm 7 \%$ SEM. We next used a phase histogram analysis to show that the reduced theta power was not caused by a decrease in the amplitude of the theta rhythm, but instead was caused by a decrease in the amount of time the EEG was in the theta state. The phase histogram analysis rejected periods of non-theta EEG before selecting theta waves for averaging. By this method, the amplitude of the average theta wave in phase histograms did not change reliably before and during muscarinic blockade: the mean CA1 theta amplitude was $0.33 \pm 0.13 \mathrm{mV}$ SEM before scopolamine and $0.30 \pm 0.12$ SEM after scopolamine $(t=1.74$; $\mathrm{df}=31 ; p>0.09)$. Similarly, the mean fissure theta amplitude was $1.12 \pm 0.33 \mathrm{mV}$ before scopolamine and $1.11 \pm 0.29 \mathrm{mV}$ after scopolamine $(t=0.84 ; \mathrm{df}=31$; $p>0.83)$. On the other hand, the algorithm used to detect highquality theta revealed that the time spent in theta was reduced by $33 \%$, which corresponds precisely to the time-averaged reduc- 
tion of power in the theta band. We conclude that the reduced time the EEG spends in the theta state is a possible explanation for the reduced firing rates of place cells after scopolamine injections.

To distinguish between a direct action of scopolamine on place cell activity and a secondary effect attributable to decreased theta and increased LIA, we took advantage of the extremely tight coupling between EEG state and locomotor activity demonstrated by Vanderwolf (1969). It was shown that theta is generated during walking or running, whereas LIA is generated during repetitive activities such as grooming, eating, and drinking and, crucially, during quiet alertness. Moreover, the correlation between theta/non-theta and walking/stationary was hardly disturbed by high doses of atropine, a muscarinic cholinergic antagonist with actions similar to scopolamine (Vanderwolf et al., 1977).

As expected from the EEG/behavior correlation work (Vanderwolf, 1969), an analysis of running speed revealed a clear increase in the fraction of time spent at rest, from 8.9 to $15.8 \%$. We also found, however, that the correlation between decrease of the center rate in the firing field and still time was only -0.18 , so that the variance in still time accounted for only $\sim 3.2 \%$ of the variance in the center rate decrease.

In a separate analysis, we "speed clamped" data samples from control and scopolamine sessions so that firing rate analysis was done only for time intervals in which running speed was constrained to be between 5 and $40 \mathrm{~cm} / \mathrm{sec}$, where running speed was taken as the average over $0.5 \mathrm{sec}$ intervals. With this constraint, the mean center rate was 20.6 spikes per second for control sessions and 16.2 spikes per second for sessions $1 \mathrm{hr}$ after the standard scopolamine dose. A paired $t$ test shows that these means are extremely unlikely to come from the same distribution $(t=3.94$; $\mathrm{df}=65 ; p=0.00021)$. We conclude that scopolamine has a direct effect on place cell firing rate, independent of confounding with running speed.

It is important to note that the speed clamp analysis also suggests that differences in behavior in control and scopolamine sessions in fact do affect firing rate. Thus, when speed is restricted to the range between 5 and $40 \mathrm{~cm} / \mathrm{sec}$, the mean center rate during control sessions is raised from 18.7 to 20.6 spikes per second, whereas the mean center rate during scopolamine sessions shows a greater increase from 11.3 to 16.2 spikes per second. Thus, the effect of eliminating still time (and very slow movements) from consideration more strongly affects recordings made during scopolamine. Further restriction of the speed range eliminates too great a fraction of the data to allow analysis of the rate maps. Scatterplots of data for session pairs (before and $1 \mathrm{hr}$ after a standard scopolamine dose) were made for change in rate versus change in running speed (data not shown). Linear regression fits to these plots showed that most of the firing rate change was present at the $y$ intercept, where the running speed was unchanged.

The theta phase of the firing of place cells and theta cells was unaffected by intracerebroventricular scopolamine injection. The mean phase of firing of place cells $(n=40)$ was $-148^{\circ}$ for the control period and $-149^{\circ} 1 \mathrm{hr}$ after the standard dose of scopolamine (where $0^{\circ}$ represents the positive peak of the fissure theta). For the place cells, the change in phase as a result of scopolamine injection $\left(\right.$ mean $\left.=0.6^{\circ}, \mathrm{SE}=6.3^{\circ}\right)$ was not significantly different from zero $(t=0.095$; $\mathrm{df}=39 ; p=0.92)$. The mean phase for theta cells $(n=29)$ was $-109^{\circ}$ for the control period and $-106^{\circ}$ after scopolamine. For the theta cells, like the place cells, the change in phase attributable to scopolamine (mean $=8.9^{\circ}, \mathrm{SE}=$ $\left.6.6^{\circ}\right)$ was not significantly different from zero $(t=1.35$; $\mathrm{df}=28$; $p=0.19)$, nor was the phase change for theta cells different from the phase change for place cells $(p=0.37)$.

\section{The time course of scopolamine action on place cells}

The typical effects over time of a standard scopolamine dose on place cell firing are visible in the color-coded firing rate maps in Figure 1, where each row shows the outcome of four recordings sessions for a single cell; rows A1 and A2 are for a pair of simultaneously recorded $\mathrm{CA} 1$ cells, whereas rows $\mathrm{B} 1$ and $\mathrm{B} 2$ are for a pair of simultaneously recorded CA3 cells. The first map in each row is for a preinjection baseline session; the other maps are for sessions at the indicated time after the injection. The sessions at $0.5 \mathrm{hr}$ show smaller effects than those at $1 \mathrm{hr}$, indicating that the maximum effect of the scopolamine injection can be delayed, possibly because of diffusion time from the cannula tips to the site of recording. The fourth column of maps at $4 \mathrm{hr}$ after injection shows that a good deal of recovery has occurred compared with $1 \mathrm{hr}$, although decreases of activity relative to baseline are still clear in this time range.

The firing rate maps in Figure 2 were selected to show the almost complete reversal of scopolamine effects at $24 \mathrm{hr}$ after injection. For each row, it is clear that firing rates were depressed and firing patterns disrupted at $1 \mathrm{hr}$ and also that the patterns very nearly reverted to their preinjection appearance $1 \mathrm{~d}$ later. Note, particularly for the cells in Figure 2, $A$ and $B$, that the distribution as well as intensity of positional firing are considerably changed, even after $24 \mathrm{hr}$.

Because we saw no clear differences in the time course of scopolamine action on CA1 and CA3 place cells, we therefore combined units from the two areas to create the graphs of Figure 3. In all parts of Figure 3, asterisks indicate that the multivariate ANOVA showed a significant effect for that variable and the parameter value at that time differs reliably according to the Fisher's PLSD tests from the value in the control session at $t=0$. Each graph shows the value of a parameter at $t=0$ and at $0.5,1,2,3,4$, and $24 \mathrm{hr}$ after injection. The numbers near each data point in Figure $3 A$ indicate the number of cells whose average value the point represents; the decrease in the number of cells reflects waveform loss or uncertainty of identity over time.

The three firing rate estimates (overall, in-field, peak rates) show clear, persistent decreases that are already visible at $0.5 \mathrm{hr}$, reach an asymptote by $1 \mathrm{hr}$, and show a good deal of recovery by $24 \mathrm{hr}$ (Fig. 3A-C). It is possible that the incomplete recovery at 24 $\mathrm{hr}$ is caused by residual behavioral effects of the scopolamine and not a direct effect on pyramidal cells. This possibility is suggested further by the complete recovery for coherence, which otherwise showed the strongest effect of any measure (Fig. 3F). Regardless of the exact origin of the relatively long persistence of the scopolamine effect, it led us to always separate sequential drug injections in individual rats by at least $3 \mathrm{~d}$.

Neither out-of-field rate (Fig. 3D) nor field size (Fig. 3E) showed a significant overall effect of the standard scopolamine injection, nor did they differ reliably according to Fisher's PLSD from the control value at any time point. Nevertheless, the pattern of change for these variables leads us to suspect that they are modified in opposite directions by scopolamine injections. Indeed, the probability that both out-of-field rate and field size would change in the same direction at five presumably independent time points is only 1 in 32 or $\sim 3 \%$. The time course of scopolamine action on place cells therefore appears to be maximal $\sim 1 \mathrm{hr}$ after injection, with a plateau that lasts for $4-6 \mathrm{hr}$ followed by considerable or nearly complete recovery at $24 \mathrm{hr}$.

\section{The time course of scopolamine action on theta cells}

As seen in Figure 4, the time course of scopolamine effects on interneurons is reminiscent of the time course for place cells. The magnitude of the rate decreases for the interneurons is smaller 

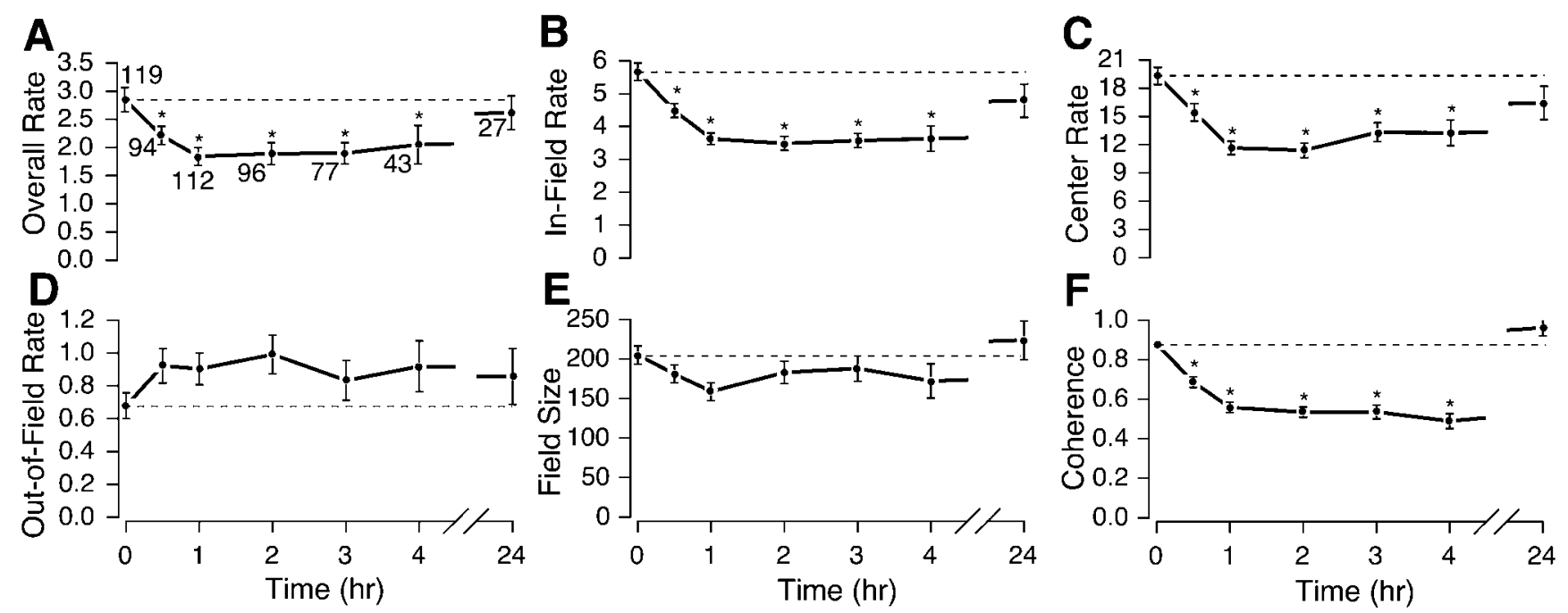

Figure 3. Time course of the effect of muscarinic blockade on the spatial firing characteristics of place cells. The dashed line in each panel shows the mean across place cells for predrug control sessions (also plotted at time $=0$ ). The mean ( \pm 1 SEM) is plotted for time after muscarinic blockade by scopolamine. The number of cells recorded at each time point is given near each data point in the overall rate plot of $A$. Values that differ from the predrug control according to the post hoc Fisher's PLSD test at least at the 0.05 level of significance are indicated with asterisks. Compared with control means, the overall mean firing rate for the session $\left(F_{(6,561)}=4.0 ; p=0.0006\right)(A)$, the mean rate in the largest firing field $\left(F_{(6,561)}=12.9 ; p=0.0001\right)(B)$, and the rate in the center of the largest field $\left(F_{(6,561)}=10.9 ; p=0.0001\right)(C$ are all significantly reduced (multivariate ANOVA and Fisher's PLSD) from 0.5 to $4 \mathrm{hr}$ after scopolamine. The trends for elevation of average firing rate outside the field $\left(F_{(6,561)}=1.02 ; p=0.41\right)(D)$ and reduction in field size $\left(F_{(6,561)}=1.77 ; p=0.10\right)(E)$ were not significant by the ANOVA (or even for any single time point), but the probability is only 1 in 32 that all five consecutive points would lie on the same side of the mean simply by chance. The smoothness of the rate map as measured by spatial coherence $\left(F_{(6,561)}=30.8 ; p<0.0001\right)$ $(F)$ is significantly reduced between 0.5 and $4 \mathrm{hr}$ after scopolamine. None of the $24 \mathrm{hr}$ points are significantly different from controls, indicating recovery for all quantities.

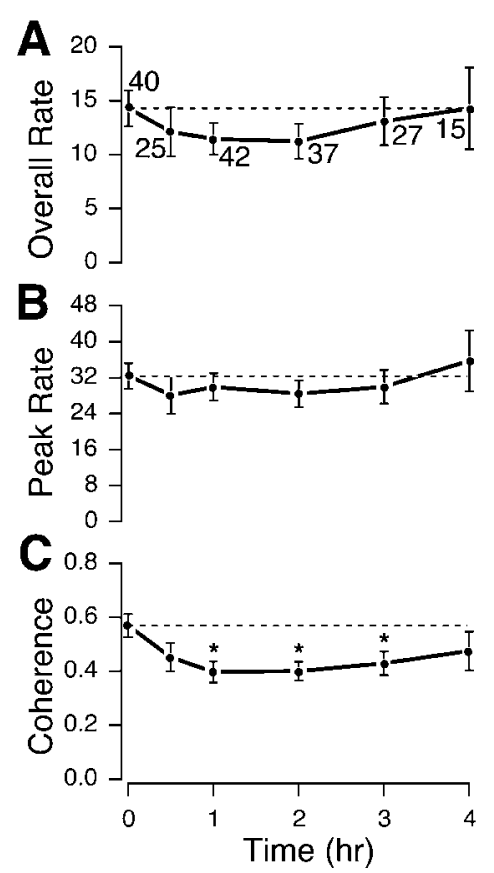

Figure 4. Time course of the effect of muscarinic blockade on the spatial firing characteristics of theta cells. Overall firing rate for the session $\left(F_{(5,180)}=0.50 ; p=0.78\right)(A)$ and peak firing in the map of average rate $\left(F_{(5,180)}=0.45 ; p=0.81\right)(B)$ each show a nonsignificant reduction after scopolamine administration; any such effect has reversed by $4 \mathrm{hr}$. The coherence of positional firing patterns for these interneurons $\left(F_{(5,180)}=2.52 ; p=0.03\right)(C)$ shows a significant decrease at 1,2, and $3 \mathrm{hr}$ after injection but has substantially recovered by $4 \mathrm{hr}$.

than for place cells and does not reach significance at any time point. Nevertheless, the peak and overall rates are lower at all but the $4 \mathrm{hr}$ time point after the scopolamine injection and moreover are little different at $4 \mathrm{hr}$ from the control value. Coherence, on the other hand, undergoes a strong decrease by $0.5 \mathrm{hr}$ that persists up to $3 \mathrm{hr}$ after injection; at $4 \mathrm{hr}$, the mean coherence is lower than at $t=0$, but the difference is not reliable. Overall, scopolamine appears to disrupt the local smoothness of theta cell firing patterns over a considerable interval and also tends to decrease their activity, possibly because of increases in still time when interneuron discharge is expected to slow.

\section{Dose-response effects of intracerebroventricular scopolamine}

In addition to the standard dose of $3.0 \mu \mathrm{g}$ in each ventricle, we tested the effects of half doses ( $1.5 \mu \mathrm{g}$ in each ventricle) and double doses $(6.0 \mu \mathrm{g}$ in each ventricle). Dose measurements were made only for CA3 cells. Dose-response data were not collected while recording in CA1 to avoid any potential long-term effects of high doses of the drug that might interfere with later CA3 recordings from the same animal. Once again, all of the rate measures behaved in the same way; progressively greater rate decreases were seen at the half and standard doses, but no additional decrease was seen at the double dose (Fig. $5 A-C$ ). In contrast to the rate measures, the three scopolamine doses caused progressively greater decreases in field size (Fig. 5E) and coherence (Fig. 5F). Thus, although firing rate on average did not decrease further at the double dose, there was additional degradation of location-specific firing.

\section{Discussion}

We investigated the effects of bilateral intracerebroventricular injections of the muscarinic antagonist scopolamine on the activity of hippocampal place cells. We found that $3.0 \mu \mathrm{g}$ per ventricle doses reduced place cell discharge rate and decreased the local smoothness of positional firing patterns over a time course of $\sim 1$ $\mathrm{hr}$ after injection. These effects are attributable to the synergistic operation of two mechanisms. (1) Scopolamine tends to reduce the amount of time the hippocampal EEG dwells in the theta state. This shift alone is associated with decreases of in-field firing and increases of out-of-field firing by place cells (Kubie et al., 1985). (2) When analysis of spike activity is restricted to intervals 


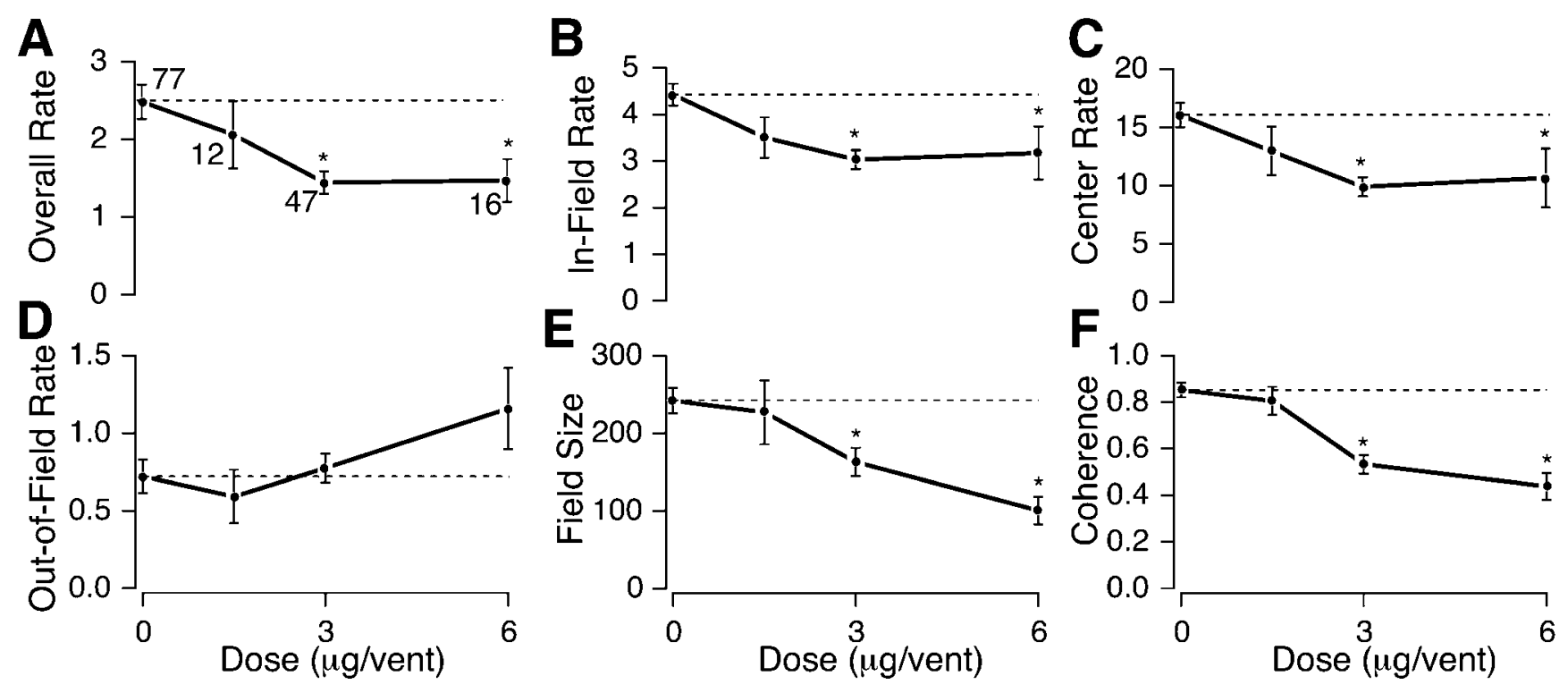

Figure 5. Dose-response curves for intracerebroventricular scopolamine. The effects of $1.5,3.0$, and $6.0 \mu \mathrm{g}$ per ventricle of scopolamine on the place cell measures overall rate $\left(F_{(3,148)}=4.88\right.$; $p=0.003)(A)$, in-field rate $\left(F_{(3,148)}=6.33 ; p=0.0005\right)(B)$, center rate $\left(F_{(3,148)}=6.20 ; p=0.0005\right)(C)$, out-of-field rate $\left(F_{(3,148)}=1.39 ; p=0.25\right)(D)$, field size $\left(F_{(3,148)}=6.33 ; p=0.0005\right)$ $(E)$, and spatial coherence $\left(F_{(3,148)}=20.7 ; p<0.0001\right)(F)$ are plotted (mean \pm 1 SEM). The number of cells for each dose is indicated near the data points in $A$, and asterisks mark data points that differ significantly from the control value (dashed line). The dose-response curves show saturation for the overall, in-field, and field center rate measures. Out-of-field rate shows a rather large increase at the highest scopolamine dose. The decreases of field size and coherence are progressively greater at higher doses.

in which the rat is moving so that the hippocampal EEG is only in the theta state, the decrease of place cell discharge rate persists, demonstrating that a major component of the scopolamine effect on place cell activity is behavior independent.

A separate indication of a behavior-independent effect is provided by rotational analysis, which reveals that scopolamine reduces the reproducibility of positional firing patterns in two senses. (1) The angle at which the peak correlation occurs between the firing distributions in a reference session and in a second session increases considerably after scopolamine injection. (2) The maximal correlation between the firing distribution in a reference session and a second session decreases considerably after scopolamine injections.

The $3.0 \mu \mathrm{g}$ per ventricle dose of scopolamine also decreased the local smoothness of interneuron spatial firing patterns and produced small, unreliable firing rate decreases. The scopolamineinduced changes of activity in both place cells and interneurons were reversible; recovery took $>4 \mathrm{hr}$ for place cells and was nearly complete by $24 \mathrm{hr}$, whereas interneurons appeared to return to their initial state over a briefer time course of $\sim 4 \mathrm{hr}$.

Our data do not tell us whether either scopolamine effect is local to the hippocampus, but the route of administration and the exposure of the hippocampus to the ventricles leave open the possibility that receptor blockade occurs on place cells, hippocampal interneurons, or intrahippocampal axon terminals whose transmitter release is modulated by acetylcholine.

In addition to investigating the kinetics of scopolamine action, we also showed that its effects were dose dependent. Bilateral injections of $1.5 \mu \mathrm{g}$ scopolamine had only weak effects on place cells $1 \mathrm{hr}$ later. Bilateral doses of $6.0 \mu \mathrm{g}$ had rather complex effects; they produced no greater decrease in firing rate measures than did the $3.0 \mu \mathrm{g}$ (standard) dose, but caused a rather large increase in out-of-field firing and also caused additional decreases in field size and coherence.

These results imply that muscarinic cholinergic transmission normally enhances location-specific firing in CA1 and CA3 pyramids. Muscarinic blockade causes the positional firing of most place cells to be weaker and less selective than normal. A remarkable aspect of scopolamine action is that it closely resembles, both qualitatively and quantitatively, the change in place cell activity seen in physiological conditions when the hippocampal EEG switches from theta to LIA: both cause decreased in-field rate, decreased field precision, and a trend toward increased out-offield firing (Kubie et al., 1985; Foster et al., 1989). The origin of these correspondences is likely the cholinergic transmission that underlies the "atropine-sensitive" component of theta, a component that is abolished by high doses of muscarinic antagonists (Vanderwolf et al., 1977). Direct measurements of acetylcholine release in the hippocampus reveal that it is twice as high during running, a theta-related activity, than during rest, an LIA-related state (Dudar et al., 1979). By inference, the near doubling of discharge rate by cholinergic rhythmically bursting septohippocampal neurons during urethane-induced theta also implies an EEG-state modulation of acetylcholine release (Stewart and Fox, 1989). We therefore suggest that persistent blockade of muscarinic cholinergic receptors by scopolamine mimics the decreased occupancy of cholinergic muscarinic receptors produced by switches from theta to LIA.

\section{Positional firing properties and muscarinic actions in the hippocampus}

By what processes does activation of muscarinic receptors cause place cell discharge to accelerate and get more precise? We focus on three mechanisms that, in combination, could produce the observed changes in positional firing after a switch from LIA to theta in normal rats and the observed effects on place cells of scopolamine intoxication. Our model is consistent with recent evidence that place fields require only direct entorhinal-hippocampal circuitry (Brun et al., 2002). We present our current hypothesis, which is consistent with the data up to now, but other explanations may exist.

The first mechanism is suppression of glutamatergic transmission caused by activation of presynaptic muscarinic receptors (Valentine and Dingledine, 1981; Segal, 1989; Sheridan and Su- 
tor, 1990). A key feature of this suppression is that it is selective for inputs to the proximal dendrites in stratum radiatum compared with inputs to the distal dendrites in stratum lacunosummoleculare (Hasselmo and Schnell, 1994; Hasselmo et al., 1996). On this basis, acetylcholine causes control over CA1 pyramidal cell activity to shift in favor of extrinsic (perforant path) compared with associational (Schaffer collateral) inputs. Selective muscarinic suppression of activity in CA3 has not been shown but is likely to exist based on the similar effects of scopolamine on CA1 and CA3 place cells.

Why should differential muscarinic suppression of glutamatergic transmission cause place cell specificity to be enhanced? We propose it is because the location-specific discharge of place cells depends mainly on highly processed sensory information provided by the separate perforant path inputs to CA3 and CA1 so that place cell activity is generated independently in both areas. In this view, signals sent along the trisynaptic path may be critical for computing optimal paths by retrieving information stored in a cognitive map, rather than the primary basis of synthesis of location-specific discharge. This view has similarities to the proposal that selective muscarinic suppression of associational compared with extrinsic inputs allows for the storage of new information without interference by established memories (Hasselmo et al., 1992).

Acetylcholine may also affect place cell discharge by increasing the discharge of inhibitory interneurons. This activation is mediated primarily by nicotinic receptors on interneurons (Frazier et al., 1998; Brazhnik et al., 1999 ). Despite the capacity for muscarinic suppression of GABA release (Pitler and Alger, 1992), increases of interneuron discharge during theta rhythm (Fox and Ranck, 1975, 1981) enhance the somatic inhibition of pyramidal cells (Fox, 1989; Ylinen et al., 1995), further reducing the ability of proximal, nonspatial inputs to fire the cell.

Although the differential muscarinic suppression of transmission and enhanced somatic inhibition could explain enhanced place cell specificity during theta and reversal of this enhancement by scopolamine, these two effects alone should cause increases instead of decreases in firing rate during muscarinic blockade. The observed firing rate changes can be accounted for, however, by postsynaptic muscarinic-based decreases of potassium currents that increase cell excitability by increasing input resistance, reducing post-spike hyperpolarization, and reducing spike frequency adaptation (Ben-Ari et al., 1981; Benardo and Prince, 1982; Cole and Nicoll, 1984; Oh et al., 1999). Our model also depends on the ability of distal dendrites of pyramidal cells to generate action potentials. We imagine that during theta the combined proximal suppression of transmitter release and increased somatic inhibition prevent proximal inputs from activating the axon hillock (proximal) trigger zone. In contrast, we suppose that the perforant path inputs can activate the dendritic (distal) trigger zone more effectively as a result of the decreased potassium conductance of the dendritic membrane. Finally, the regenerative activity initiated in the distal dendrites, unlike the proximal EPSPs, is able to activate the proximal trigger zone despite the somatic shunting, resulting in full-scale action potentials that occur during theta in a precise location-specific manner. We summarize in Figure 6 the features of this working hypothesis of why place cell discharge is different during theta and LIA. Our conclusions are in good agreement with the work of Buzsaki and colleagues (Buzsaki, 2002), whose two-state model encompasses a wide variety of additional phenomena.

Spatial behavior, place cells, and scopolamine

According to the spatial mapping theory of hippocampal function (O'Keefe and Nadel, 1978), the disruption of place cell activity

\section{HIPPOCAMPUS}

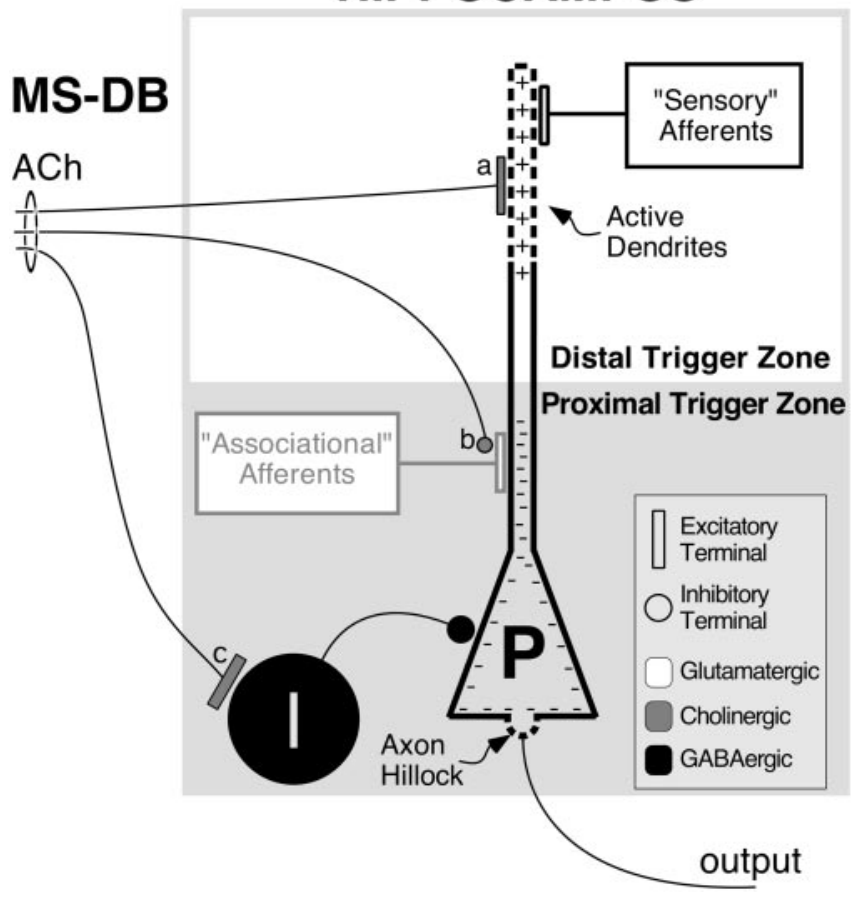

Figure 6. Scheme for how mechanisms of muscarinic transmission might produce the observed effects of scopolamine administration on place cells. Enhanced release of acetylcholine $(A C h)$ by activity in afferents from the medial septal nucleus and nucleus of the diagonal band of Broca (MS-DB) during theta rhythm. a turns off potassium currents, increasing pyramidal cell $(P)$ excitability $(+), b$ suppresses proximal intrinsic ("Associational" Afferents) excitatory connections relative to distal extrinsic ("Sensory" Afferents) excitatory connections, and c activates interneurons $(I)$, producing increased somatic inhibition $(-)$. The latter two effects ( $b$ and $c$ ) work together to suppress out-of-field firing of place cells by reducing the effectiveness of afferent activity from other hippocampal place cells ( grayed area). The first effect, reduction of potassium currents $(a)$, enhances the in-field firing by triggering spikes in the dendrites that prevail despite the somatic inhibition and activate the axon (output). Dashed lines represent the "trigger zones" in the pyramidal cell membrane at the axon hillock and in the apical dendrites. According to this scheme, acetylcholine effectively switches the pyramidal cell from suppression of its distal inputs by high potassium conductance and heavily weighting its proximal inputs as integrated by the axon hillock (Proximal Trigger Zone) to suppression of its proximal inputs by somatic inhibition and heavily weighting its distal inputs as integrated by the active membrane in the apical dendrites (Distal Trigger Zone). Additional considerations are given in Results.

caused by scopolamine should impair the ability of rats to learn and perform in complex navigational tasks. In agreement with this prediction, performance in the Morris swimming task was degraded during intoxication by atropine, another muscarinic antagonist (Sutherland et al., 1982). A great deal of subsequent work confirms that muscarinic blockade slows acquisition and impairs performance in complex spatial tasks (Hagan and Morris, 1988; Rush, 1988; Whishaw, 1989; Fibiger, 1991). It is important to note that the learning deficit could result from abnormal positional firing, without any need for scopolamine to directly affect mechanisms of plasticity; it is easy to imagine that a map formed during scopolamine intoxication would not be a veridical representation of the layout of the environment. The fact that scopolamine actually modifies synaptic plasticity processes (Markram and Segal, 1990; Patil et al., 1998) provides an additional reason for expecting muscarinic blockade to result in abnormal learning.

\section{References}

Benardo LS, Prince DA (1982) Cholinergic excitation of mammalian hippocampal pyramidal cells. Brain Res 249:315-331.

Ben-Ari Y, Krnjevic K, Reinhardt W, Ropert N (1981) Intracellular obser- 
vations on the disinhibitory action of acetylcholine in the hippocampus. Neuroscience 6:2475-2484.

Bostock E, Muller RU, Kubie JL (1991) Experience-dependent modifications of hippocampal place cell firing. Hippocampus 1:193-205.

Brazhnik ES, Fox SE, Muller RU (1994) Either blockade or enhancement of cholinergic transmission affects the location-specific firing of hippocampal pyramidal cells. Soc Neurosci Abstr 20:343.

Brazhnik ES, Borgnis RL, Fox SE (1999) Nicotinic receptors modulate the location-specific firing of CA1 place cells. Soc Neurosci Abstr 25:1391.

Brun VH, Otnaess MK, Molden S, Steffenach HA, Witter MP, Moser MB, Moser EI (2002) Place cells and place recognition maintained by direct entorhinal-hippocampal circuitry. Science 296:2243-2246.

Buzsaki G (2002) Theta oscillations in the hippocampus. Neuron 33:325-340.

Cole AE, Nicoll RA (1984) The pharmacology of cholinergic excitatory responses in hippocampal pyramidal cells. Brain Res 305:283-290.

Csicsvari J, Hirase H, Mamiya A, Buzsaki G (2000) Ensemble patterns of hippocampal CA3-CA1 neurons during sharp wave-associated population events. Neuron 28:585-594.

Dudar JD, Whishaw IQ, Szerb JC (1979) Release of acetylcholine from the hippocampus of freely moving rats during sensory stimulation and running. Neuropharmacology 18:673-678.

Fibiger HC (1991) Cholinergic mechanisms in learning, memory and dementia: a review of recent evidence. Trends Neurosci 14:220-223.

Foster TC, Castro CA, McNaughton BL (1989) Spatial selectivity of rat hippocampal neurons: dependence on preparedness for movement. Science 244:1580-1582.

Fox SE (1989) Membrane potential and impedance changes in hippocampal pyramidal cells during theta rhythm. Exp Brain Res 77:283-294.

Fox SE, Ranck Jr JB (1975) Localization and anatomical identification of theta and complex spike cells in dorsal hippocampal formation of rats. Exp Neurol 49:299-313.

Fox SE, Ranck Jr JB (1981) Electrophysiological characteristics of hippocampal complex-spike cells and theta cells. Exp Brain Res 41:399-410.

Fox SE, Wolfson S, Ranck Jr JB (1986) Hippocampal theta rhythm and the firing of neurons in walking and urethane anesthetized rats. Exp Brain Res 62:495-508.

Frazier CJ, Rollins YD, Breese CR, Leonard S, Freedman R, Dunwiddie TV (1998) Acetylcholine activates an alpha-bungarotoxin-sensitive nicotinic current in rat hippocampal interneurons, but not pyramidal cells. J Neurosci 18:1187-1195.

Hagan JJ, Morris RGM (1988) The cholinergic hypothesis of memory: a review of animal experiments. In: Handbook of psychopharmacology, Vol. 20, pp. 237-324. New York: Plenum.

Hasselmo ME, Schnell E (1994) Laminar selectivity of the cholinergic suppression of synaptic transmission in rat hippocampal region CA1: computational modeling and brain slice physiology. J Neurosci 14:3898-3914.

Hasselmo ME, Anderson BP, Bower JM (1992) Cholinergic modulation of cortical associative memory function. J Neurophysiol 67:1230-1246.

Hasselmo ME, Wyble BP, Wallenstein GV (1996) Encoding and retrieval of episodic memories: role of cholinergic and GABAergic modulation in the hippocampus. Hippocampus 6:693-708.

Kentros C, Hargreaves E, Hawkins RD, Kandel ER, Shapiro M, Muller RU (1998) Abolition of long-term stability of new hippocampal place cell maps by NMDA receptor blockade. Science 280:2121-2126.

Kubie JL (1984) A driveable bundle of microwires for collecting single-unit data from freely-moving rats. Physiol Behav 32:115-118.

Kubie JL, Muller RU, Fox SE (1985) Firing fields of hippocampal place cells: interim report. In: Electrical activity of the archicortex (Buszaki G, Vanderwolf CH, eds), pp 221-231. Budapest: Hungarian Academy of Science.

Kubie JL, Muller RU, Bostock E (1990) Spatial firing properties of hippocampal theta cells. J Neurophysiol 10:1110-1123.
Markram H, Segal M (1990) Long-lasting facilitation of excitatory postsynaptic potentials in the rat hippocampus by acetylcholine. J Physiol (Lond) 427:381-393.

Marshall L, Henze DA, Hirase H, Leinekugel X, Dragoi G, Buzsaki G (2002) Hippocampal pyramidal cell: interneuron spike transmission is frequency dependent and responsible for place modulation of interneuron discharge. J Neurosci 22:RC197(1-5).

Muller RU, Kubie JL, Ranck Jr JB (1987) Spatial firing pattern of hippocampal complex-spike cells in an fixed environment. J Neurosci 7:1935-1950.

Oh MM, Power JM, Thompson LT, Moriearty PL, Disterhoft JF (1999) Metrifonate increases neuronal excitability in CA1 pyramidal neurons from both young and aging rabbit hippocampus. J Neurosci 19:1814-1823.

O'Keefe J, Nadel L (1978) The hippocampus as a cognitive map. Oxford: Oxford UP.

O'Keefe J, Recce M (1993) Phase relationships between hippocampal place units and the EEG theta rhythm. Hippocampus 3:317-330.

Patil MM, Linster C, Lubenov E, Hasselmo ME (1998) Cholinergic agonist carbachol enables associative long-term potentiation in piriform cortex slices. J Neurophysiol 80:2467-2474.

Pitler TA, Alger BE (1992) Cholinergic excitation of GABAergic interneurons in the rat hippocampal slice. J Physiol (Lond) 450:127-142.

Rush DK (1988) Scopolamine amnesia of passive avoidance: a deficit of information acquisition. Behav Neural Biol 50:255-274.

Segal M (1989) Presynaptic cholinergic inhibition in hippocampal culture. Synapse 4:305-312.

Sheridan RD, Sutor B (1990) Presynaptic M1 muscarinic cholinoreceptors mediate inhibition of excitatory synaptic transmission in the hippocampus in vitro. Neurosci Lett 108:273-278.

Skaggs WE, McNaughton BL, Wilson MA, Barnes CA (1996) Theta phase precession in hippocampal neuronal populations and the compression of temporal sequences. Hippocampus 6:149-172.

Stewart M, Fox SE (1989) Firing relations of medial septal neurons to the hippocampal theta rhythm in urethane anesthetized rats. Exp Brain Res 77:507-516.

Sutherland RJ, Whishaw IQ, Regehr JC (1982) Cholinergic receptor blockade impairs spatial localization by use of distal cues in the rat. J Comp Physiol Psychol 96:563-573.

Thompson LT, Best PJ (1990) Long-term stability of the place-field activity of single units recorded from the dorsal hippocampus of freely behaving rats. Brain Res 509:299-308

Valentine RJ, Dingledine R (1981) Presynaptic inhibitory effect of acetylcholine in the hippocampus. J Neurosci 1:784-792.

Vanderwolf CH (1969) Hippocampal electrical activity and voluntary movement in the rat. Electroencephalogr Clin Neurophysiol 26:407-418.

Vanderwolf CH, Kramis R, Robinson TE (1977) Hippocampal electrical activity during waking behaviour and sleep: analyses using centrally acting drugs. Ciba Found Symp 58:199-226.

Vanderwolf CH, Leung LW, Cooley RK (1985) Pathways through cingulate, neo- and entorhinal cortices mediate atropine-resistant hippocampal rhythmical slow activity. Brain Res 347:58-73.

Whishaw IQ (1989) Dissociating performance and learning on spatial navigation tasks in rats subjected to cholinergic muscarinic blockade. Brain Res Bull 23:347-358.

Ylinen A, Soltesz I, Bragin A, Penttonen M, Sik A, Buzsaki G (1995) Intracellular correlates of hippocampal theta rhythm in identified pyramidal cells, granule cells and basket cells. Hippocampus 5:78-90.

Zebrowska-Lupina I, Kleinrok Z, Poddubiuk Z (1975) Central action of drugs acting on the cholinergic muscarinic receptor. III. Influence of atropine and scopolamine injected intraventricularly on behavior and levels of biogenic amines in the rat brain. Arch Immunol Ther Exp 23:485-495. 